Article

\title{
Development Strategy for Sustainable Solar Home System in the Akha Upland Community of Thailand
}

\author{
Pimnapat Bhumkittipich ${ }^{1, *}$ and Hideaki Ohgaki ${ }^{2}$ (i) \\ 1 Department of Social Sciences and Humanities, Faculty of Liberal Arts, Rajamangala University of \\ Technology Thanyaburi, Thanyaburi, Pathumtani 12110, Thailand \\ 2 Institute of Advanced Energy, Kyoto University, Gokasho, Uji, Kyoto 611-0011, Japan; \\ ohgaki.hideaki.2w@kyoto-u.ac.jp \\ * Correspondence: pimnapat_i@rmutt.ac.th; Tel.: +66-2-549-4960
}

Received: 15 May 2018; Accepted: 4 June 2018; Published: 10 June 2018

\begin{abstract}
With the growing effects of global warming and carbon pollution, environmental protection has become an urgent necessity. In addition, solar energy has been accepted worldwide for the generation of electricity. However, remote areas in Thailand have not had effective solar home system (SHS) development. This paper aims to explore the problems of SHS development and analyze the external factors that could have an impact on their operation in the Akha upland community of Thailand. The result of the survey indicates that about $79.38 \%$ of the respondents displayed a high-level lack of information and repair work. Moreover, many respondents presented low-level satisfaction in developing SHS. There are four strategies for sustainable SHS development using a factor analysis process, these include creating approval of SHS technologies $24.93 \%$, developing SHS management $22.64 \%$, promoting SHS technologies $14.29 \%$, and supporting SHS policies $10.97 \%$. In particular, this study considered the public views on the role of an organization that could lead to sustainable development of SHS. Furthermore, these should be managed suitably for each community. As a result, this study has provided some valuable references for SHS promotion in Thailand.
\end{abstract}

Keywords: remote areas; solar home system; sustainable development; public opinion

\section{Introduction}

In the world today, it has been found that there is a tendency towards global warming getting more severe, thanks to the increasing amount of greenhouse gas (GHG). The main cause of this is the increase of $\mathrm{CO}_{2}$ that has been emitted from industrial factories as well as the energy industry, which relies on fossil fuel. Therefore, many countries have shown efforts to make the use of renewable and alternative energy more practical, in order to become low carbon societies. Solar energy technology promotion is increasing throughout the world, with supportive policies in many countries, such as Germany and other countries across Europe, and soaring production in China, Canada, and other parts of the world. Solar energy technology adoption is an important real-world phenomenon, a technology becoming progressively more sought after, as it is becoming a more economically viable alternative to a fossil fuel based on electricity generation [1]. The highlights of solar technology opportunities are, for example, as a source of carbon free power. Solar energy is currently the only practical primary source that is of sufficient abundance that is able to sustain growing energy demands for centuries to come. However, the limitation on pleasure is to keeping this an isolated resource. Technology limitations have not been sufficiently researched for political reasons [2,3]. However, the current capacity is sufficient for utilizing small-scale solar or suburban technology [4]. As for Thailand, there has been a policy concerning energy from the government, namely, by supporting investment in national projects like clean energy, railway system, electric transportations, water, and waste management, as well as putting the knowledge from researchers 
and development plans on Thai innovations so as to be used properly [5]. The large-scale renewable energy project that was conducted by the Thai government was called the Electrical Service Acceleration Project by Photovoltaic (PV) system (solar home system: SHS).The installed SHS consisted of four parts, namely: a $120 \mathrm{Wp}$ PV module, the low-cost controller (charger and inverter), 125 Ah battery, and AC load $(2 \times 10$ Watt fluorescent and 14 inch color television) (Figure 1$)$.

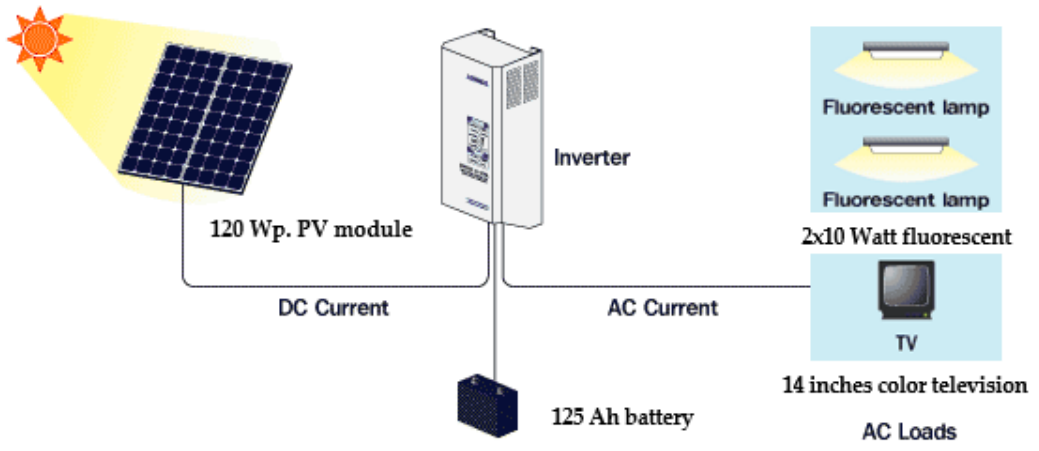

Figure 1. Sample application of PV standalone system in remote areas, Thailand [6].

The cost investment for SHS is around 238.75 Million USD [7]. The purpose of the project is to improve the social well-being of the citizens in remote areas by installing PV standalone systems where electricity lines cannot reach, in a total of 203,000 households, from 2005-2006. Most of the households are located in Northern Thailand, mostly in protected forests and mountains. According to the project follow-up, SHS did not succeed as it was expected, as a result of the lack the community's budget for maintenance, the continual of support from governmental SHS policy, and the peoples' cooperation [8]. Based on the literature review, many studies that had focused on renewable energy had made way for the discovery of methods that could have improved the sustainable use of renewable energy by examining the steps and ways to increase its effectiveness through modeling, planning, and controlling problems. As part of the study, mathematic equations were developed for other proper use [9]. Additionally, a decision analysis and knowledge on the roles of renewable energy in protecting the environment under the concept of sustainable development were applied in order to make precise policies so as to improve the energy system under the given physical capabilities [10] and to present the overall picture of the development plan and the scope of the $\mathrm{CO}_{2}$ reduction [11]. Moreover, some researchers had studied a method to optimize the allocations of the PVs and energy storage systems (ESSs), based on vulnerability analysis. They utilized the proposed concept of 'slow' and 'fast' ESSs [12]. In terms of the social acceptance of renewable energy technologies (RETs), the study covered the topic of awareness and willingness to invest in the renewable energy technology [13], but it did not consider the allocation of SHS sustainable development. What is still needed to be studied is development strategy for improving social well-being, which relies on the analysis of external factors, including politics, economy, technology, and society. Although the factors cannot be controlled, they give the information that is needed to discover the way to create opportunities that can develop SHS through factor analysis. The content of the study is presented in the following sequence: theoretical framework, methodology, data collection and results, discussion, conclusions, and recommendation.

\section{Theoretical Framework}

\subsection{Concept of Developing SHS Technology}

In the past, the concept of developing renewable energy technology was focused on the concept of sustainable development (SD), as follows: engineering, economics, and environment. The goal of which is to achieve the balance between environmental sustainability, economic sustainability, and socio-political sustainability, such as a framework for the development of sustainability 
indicators to assess renewable energy technology, which takes into consideration the economic, social, environmental, and technical factors [14]. On the other hand, the basic sustainability indicators for renewable energy systems are the most popular means of economic indicators and social indicators, and the $\mathrm{CO}_{2}$ emission is the indicator of the environmental criteria [15]. In the economic consideration, the cost indicator is widely used to analyze the system quality. A lower value of cost is more attractive from users.. There are two common social indicators, namely, job creation and the number of residents that are benefited. However, there is currently no theoretical consensus on the definition of the sustainable community [16].

In this paper, the researchers defined the meaning of SD that came out of decision-making process under the issue of community. However, SHS is considered as the new innovation of the Akha society. There are a variety of benefits to adopting an SHS. The government provides a better quality of life in the long run, compared with the non-electric sources of light at night and the news from the television. SHS has considered that the starting point leads to an acceptance of the renewable technology. It means a positive attitude toward the end-users of the SHS. However, the main barriers to process the SHS include a lack of knowledge regarding the people in remote areas and a lack of skilled workers to install and maintain the SHSs. It is important to understand the needs of electrical users and the characteristics of the target communities. What method can lead to the important sustainable development of SHSs?

\subsection{External Analysis}

The external environment is still the most important factor of strategic management, so it can be assumed that the external environment influences the performance of the system or organization [17]. The external analysis is a type of macro environment analysis on the information regarding the changes in the factors that cannot be controlled by the organization. It is a tool for help in the private or public sectors, in order to prepare and respond to the effects of changes. The external environment has been grouped into P-E-S-T (political, economic, social-cultural, and technology). However, it is also worth noting that the four paradigms of P-E-S-T will have different priorities, depending on the type of business [18]. Thus, the concept and scope of the P-E-S-T analysis has been summarized into four classifications that consist of political factors (factors related to changes in the political situation that affects the boundary of the research), economic factors (normal economic factors, such as changes in interest rates that affect the business), social factors (social change factors that are related to people's daily life, such as attitudes, culture, etc.) and technological factors (factors that are related to changes in technology, which lead to new products, or improvements in existing products, or new techniques related to exchange, etc.).

This research had applied the mentioned concept so as to create the external environment that affects the SHS development factor indicators, based on the focus group and in-depth interviews with the people involved. The results of this step will be taken so as to create appropriate questions for household interviews. However, the specific topics and the number of external factors in this study depend on the experience, skills, and ideas of the key-informant. Figure 2 shows the scope of the P-E-S-T analysis, based on the SHS project.

The results of the P-E-S-T analysis are shown by the mean value $(\bar{X})$ and standard deviation (S.D.), so as to offer the level of external factors that influence the SHS. In this respect, the findings that were obtained by the problem-solving strategies have relevance to the goals of the community, which are consistent with the bottom-up from the factor analysis method. The conceptual framework of this study, is shown in Figure 3.

The aims of this research is to study the problems and satisfaction of SHS and to find out the external factors affecting the sustainable SHS development, and to analyze the development strategies for achieving sustainable SHS in the Akha upland community of Thailand. 


\begin{tabular}{|l|l|}
$\begin{array}{l}\text { Political factors - concerning } \\
\text { policies and regulations of the } \\
\text { government that might positively } \\
\text { or negatively affect the SHS } \\
\text { operation }\end{array}$ & $\begin{array}{l}\text { Economic factors - concerning } \\
\text { the economy both in and out of the } \\
\text { community under SHS operation }\end{array}$ \\
\hline $\begin{array}{l}\text { Social factors - relating to social } \\
\text { happenings and cultures; } \\
\text { including the structure of the } \\
\text { society in the SHS operation }\end{array}$ & $\begin{array}{l}\text { Technological factors -concerning } \\
\text { the changes in technologies that } \\
\text { affect the SHS operation }\end{array}$ \\
\hline
\end{tabular}

Figure 2. The paradigms of P-E-S-T (political, economic, social-cultural, and technology), based on the solar home system (SHS) project. Source: produced by the authors (2017).

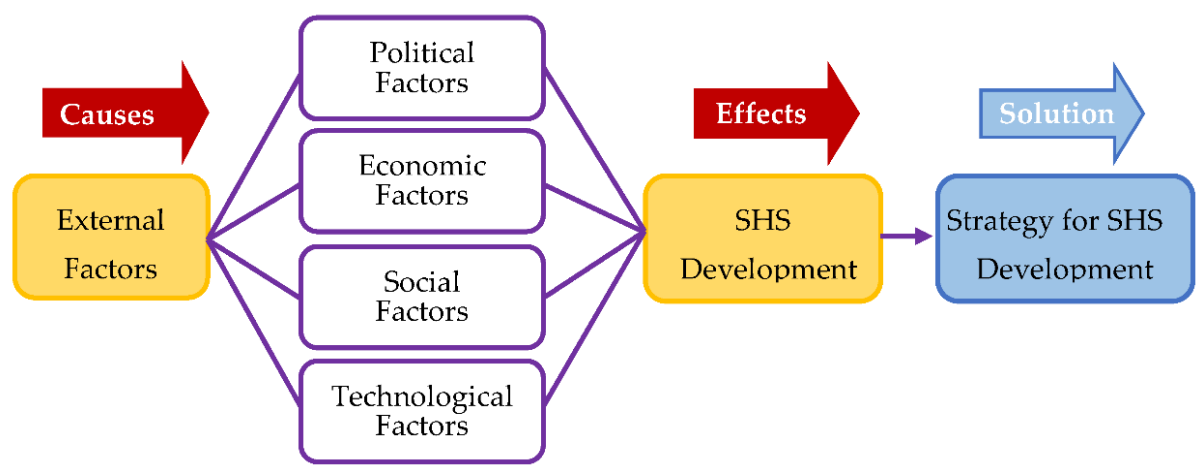

Figure 3. Framework to analyze the development strategy for sustainable SHS.

\section{Methodology}

The present study was part of a cross-sectional survey that was designed to assess the dietary patterns in a representative sample of rural households from the Akha upland community in Mae Salong Nai, Chiang Rai province, Thailand (Figure 4). Having been under the care of the energy service expansion project, the community was provided with a solar energy generating system. This research used a mixed method by applying the methodology of quantitative and qualitative research to find out the external factors that were affecting the sustainable SHS development.

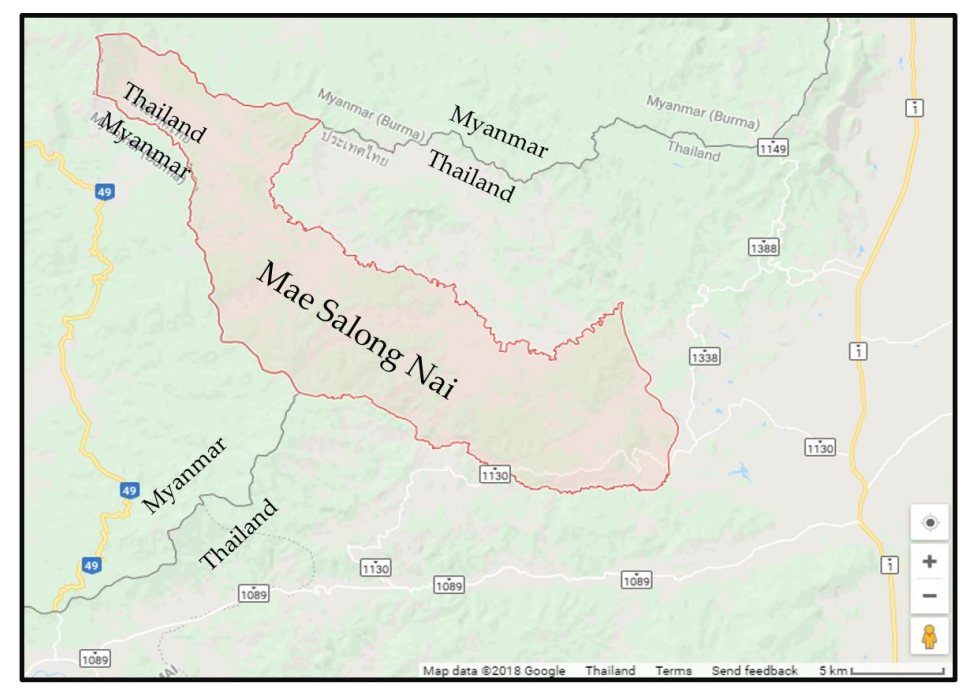

Figure 4. Map of study location, Mae Salong Nai, Chiang Rai, Thailand [19]. 


\subsection{Population and Research Samples}

This study was a research survey. The researcher conducted this study in February-April 2014. The population of the monitored data were 127 households that received services from the SHS project. Random sampling was used to select the cases, which consisted of a total of 97 cases, and was done using the formula of Yamane (1967: p. 886) [20]. Semi-structured, face-to-face, end-users interviews consisted of objective answers regarding two-three problems and satisfactions with the development of SHS. Purposive sampling was used to select key-informants, which consisted of 18 experts, including village leaders or representatives, the researchers, and academicians. Key-informant interviews were conducted so as to assess the currency of SHS in the study area and to brainstorm the concept to create the external environment and SHS development factor indicators that consisted of political, social, and technological factors (objective two).

\subsection{The Stage of This Research and Research Instrument}

Regarding the case study methodology, information from various data resources was included in three stages, as listed below.

\subsubsection{Stage One Survey and Empirical Information}

The first step applied the field research as follows: survey area, in-depth interview, non-participant observation, and literature review. This was done by analyzing the respondents' relationship with the social context and environment. This was to be done as an open-end question for quantitative data collection from the second step.

\subsubsection{Stage Two Questionnaire Development}

In this section, the research tools have been reported. The second stage was the interview with the household sampling. The interview question was divided into three parts, which included part 1 , which had elicited the respondents' background information (i.e., demographic data); part 2 focused on the satisfaction of the SHS technologies; and part 3 focused on obtaining the ideas regarding the development of SHS.

Part two and part three were answered on a three-point Likert-type scale, which ranged from 3 (strongly) to 1 (disagree). Therefore, the average rating interpreted using three levels of translation criteria, as follows:

- The average rating between 2.34 and 3.00 referred to a high.

- The average rating between 1.68 and 2.33 referred to moderate.

- The average rating between 1.00 and 1.67 referred to low.

\subsubsection{Stage Three Data Analysis}

The third stage of this study involved the statistics variables that were used, which were percentages, means, standard deviation, and factor analysis. Therefore, the article gave weight to the external environment of a community so as to describe the characteristics of the problem and SHS technologies to the people, as well as to analyze the factors in order to identify what supported sustainable SHS development. For this, we needed a workforce that was equipped with suitable skills as well as education within a framework to support them.

\section{Data Analysis and Results}

In the progress, study areas, interviews of end-users in Akha community concerning SHS development such as characteristics of research samples, problems of SHS development and the SHS development policies by the government. The raw data were analyzed according to the social science methodology to depict the main barriers of the implementation of SHS. 


\subsection{Survey and Empirical Information}

Mae Salong Nai of Northern Thailand was the area of the present study. This area was the majority of the Akha community (highlands and mountains), which were in protected forests (Figure 5). Out of the 22 villages, 4 had SHS installed by the energy service expansion project, with a total of 127 households (Figure 6). The descriptive statistics of the respondents, which described the characteristics of the sample group and the evaluated data, are in Sections 4.2 and 4.3.

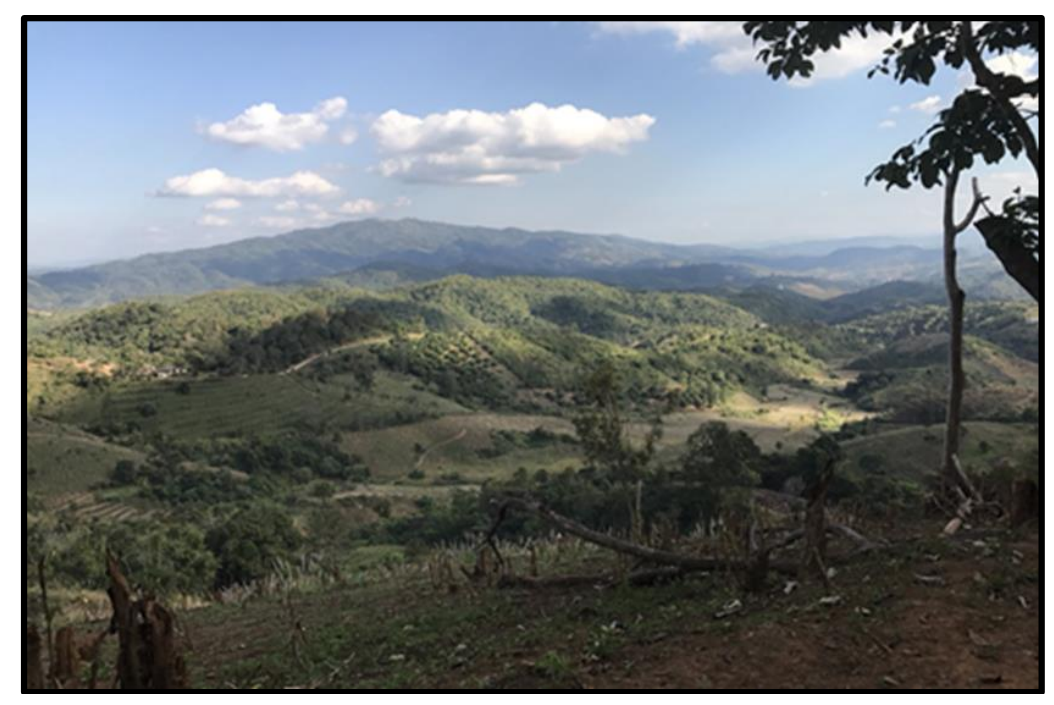

Figure 5. Geographic characteristics of Mae Salong Nai. Source: produced by the authors (2017).

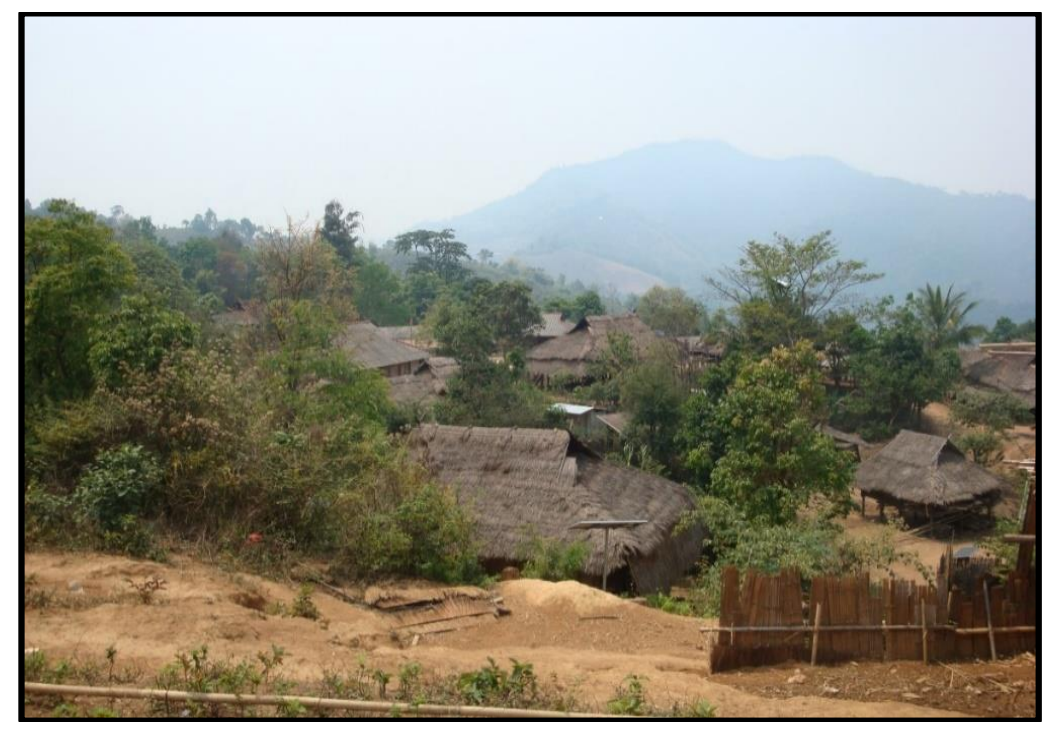

Figure 6. SHS in the Akha upland community. Source: produced by the authors (2017).

Of the 97 survey respondents, $75.10 \%$ were male, $38.14 \%$ were between $30-40$ years of age, $77.32 \%$ were uneducated, $81.14 \%$ were living as dwellers who grew rice, and $63.29 \%$ had an average income of approximately $5000 \mathrm{baht} / \mathrm{month}$. After the SHS installation, of the overall respondents, $79.38 \%$ lacked public relation concerning maintenance, $40.21 \%$ of the installed SHSs had a low usability, and for $43.30 \%$ the primary cause was the deterioration of the battery. The interviewee commented on the SHS problem in a high-level $(\bar{X}=3.16$, S.D. $=0.40)$. The main setbacks for the SHS reinstallation were insufficient funds $(\bar{X}=2.91$, S.D. $=0.38)$, the lack of coordination with the government $(\bar{X}=2.89$, 
S.D. $=0.41)$, and the lack of knowledge regarding where and how to contact a place that could provide reparation for the SHS $(\bar{X}=2.88$, S.D. $=0.41)$.

\subsection{Satisfaction of SHS Development}

The interview form regarding the SHS development consisted of 16 questions. In total, the interviewees' satisfaction level was low $(\bar{X}=1.36$, S.D. $=0.32)$. It was found that the only question that had a moderate level of satisfaction was whether the SHS was appropriate for remote areas $(\bar{X}=1.87$, S.D. $=0.85)$. In all other regards, such as the regulations on maintenance and maintenance fee collection $(\bar{X}=1.66$, S.D. $=0.60)$, whether the SHS was the suitable system for the community $(\bar{X}=1.55$, S.D. $=0.58)$, the maintenance fees $(\bar{X}=1.54$, S.D. $=0.58)$, the lifestyle, and respondents suitability with SHS usage $(\bar{X}=1.52$, S.D. $=0.52)$, a low level of satisfaction was presented.

\subsection{Identification of Factors Which Affected the Sustainable Development of SHS}

According to group discussions and in-depth interviews with 18 expert person, there were four external factors that were identified for affecting sustainable SHS development. A summary of the findings from the external factors that affected the sustainable development of the SHS domain are shown in Table 1.

Table 1. Characteristics of external factors that affected the sustainable development of solar home system (SHS).

\begin{tabular}{cl}
\hline Component & \multicolumn{1}{c}{ Description } \\
\hline \multirow{3}{*}{ Political factors } & Governmental policies on developing SHS in remote areas \\
& $\begin{array}{l}\text { Clear regulations on maintaining the SHS } \\
\text { Roles of local governmental influence or the sub-district administration organization }\end{array}$ \\
\hline \multirow{3}{*}{ Economic factors } & SHS users' socioeconomic status \\
& The initial investment for SHS reinstallation \\
& Monthly maintenance \\
& Repair/replacement fees \\
\hline & SHS users' education \\
& Increasing user population \\
& Community lifestyle and behavior (accept/deny SHS) \\
& Utility systems (electricity in/out of reach) \\
Social factors & Transportation (personal car/motorcycle/on foot) \\
& Communication with the government regarding SHS usage issues \\
\hline \multirow{3}{*}{ Technological factors } & How to use SHS \\
& How to maintain SHS \\
& How to repair SHS \\
\hline
\end{tabular}

The researchers applied the information from Table 1 in order to synthesize and design the three-point scale (on importance) interview questions that would be used on the 97 households of SHS users, which were used to find out the opinion of end-users on the factors affecting the sustainable SHS development. The results showed that the interviewees' level of satisfaction toward overall sustainable SHS development was moderately important $(\bar{X}=2.24$, S.D. $=0.47)$. Furthermore, the end-users felt political factors were important $(\bar{X}=2.54$, S.D. $=0.65)$, and a moderate importance was felt for economic factors $(\bar{X}=2.25$, S.D. $=0.54)$, social factors $(\bar{X}=2.15$, S.D. $=0.51)$, and technological factors $(\bar{X}=2.07$, S.D. $=0.75)$, as showed in Table 2.

Then, the factor analysis method was used to identify the underlying 16 items or external factors' effects on the development of SHS, and the items that best represented these factors were selected, in relation to the factors within the group. Therefore, each of the components could be described according to what the factors indicated, which proved beneficial for planning the developments. The data that were used to analyze the elements was characterized by several continuous variables that were stored in the sample group. Then, it was confirmed whether the variables were related. The factor 
analysis could be used if a variable was very relevant or had a significant relationship. If the variable was not related or was less relevant it should not have been used in the factor analysis techniques.

Table 2. External factors affecting sustainable SHS development.

\begin{tabular}{|c|c|c|c|c|}
\hline Items & Component & Mean & S.D. & Description \\
\hline & Political factors & 2.54 & 0.65 & Very important \\
\hline 1. & Government's continuity in SHS development policies & 2.59 & 0.64 & Very important \\
\hline 2. & Regulations on maintenance and maintenance fee collection & 2.52 & 0.71 & Very important \\
\hline \multirow[t]{2}{*}{3.} & Roles of the sub-district administration organization in SHS management & 2.51 & 0.71 & Very important \\
\hline & Economic factors & 2.25 & 0.54 & Moderately important \\
\hline 4. & SHS improves the household economy & 2.08 & 0.61 & Moderately important \\
\hline 5. & The initial investment for SHS installation & 2.54 & 0.69 & Very important \\
\hline 6. & Maintenance fees (e.g., for distilled water) & 2.11 & 0.76 & Moderately important \\
\hline \multirow[t]{2}{*}{7.} & SHS repair/replacement fees & 2.24 & 0.72 & Moderately important \\
\hline & Social factors & 2.15 & 0.15 & Moderately important \\
\hline 8. & SHS helps understand social changes & 1.81 & 0.75 & Moderately important \\
\hline 9. & SHS sufficient for increasing users & 2.44 & 0.66 & Very important \\
\hline 10. & SHS is proper for sufficient lifestyle & 2.04 & 0.76 & Moderately important \\
\hline 11. & SHS is suitable for remote areas & 2.05 & 0.70 & Moderately important \\
\hline 12. & SHS is the utility suitable for the community & 2.07 & 0.64 & Moderately important \\
\hline \multirow[t]{2}{*}{13.} & SHS maintenance from government officials & 2.43 & 0.78 & Very important \\
\hline & Technological factors & 2.07 & 0.75 & Moderately important \\
\hline 14. & SHS usage instruction & 1.99 & 0.80 & Moderately important \\
\hline 15. & SHS maintenance & 2.07 & 0.78 & Moderately important \\
\hline 16. & SHS device reparation & 2.13 & 0.79 & Moderately important \\
\hline Overall & & 2.24 & 0.47 & Moderately important \\
\hline
\end{tabular}

The five-major steps [21] were useful in this paper, which included the following: Step 1: precondition (evaluation of the sample size adequacy using correlation matrix, Kaiser-Meyer-Olkin [KMO] and Bartlett's test techniques [22]); step 2: factor extraction (choosing factor extraction method, such as the principal components analysis, image factoring, maximum likelihood, alpha factoring, etc.); step 3: factor rotation; (selection of rotational method, whether orthogonal rotations or oblique rotation); step 4: number of factors (such as the percentage of variance explained); and step 5: interpretation and labeling of factors (factor loadings and factor scores). This study selected the KMO statistics to use the measurement of the sample data as a value (.790), which indicated that it was appropriate to analyze the elements in good order [23]. Thus, based on the results, it was appropriate to proceed with a factor analysis to examine factors that affected the sustainable SHS development. The results of Bartlett's test $(p<0.001)$ were significant [24] if the various variants had a sign at level 0.000 , and if the factorability and sample size were excellent [25], which showed that the variables could be used to analyze the elements (Table 3).

Table 3. Values of the Kaiser-Meyer-Olkin (KMO) test and Bartlett's test.

\begin{tabular}{llc}
\hline \multicolumn{2}{c}{ Kaiser-Meyer-Olkin Measure of Sampling Adequacy } & 0.79 \\
\hline \multirow{3}{*}{ Bartlett's Test of Sphericily } & Approximate chi-square & 928.76 \\
& Degree of freedom & 105 \\
& Significant & 0.000 \\
\hline
\end{tabular}

Table 4 displays the total variance that was explained at fourth stage for the factors that were affecting the sustainable SHS development. Four factors were extracted because the survey elements were analyzed using an orthogonal rotation with a varimax method, under the conditions of variance eigenvalue greater than 1.00 . When the four factors were extracted, then $72.82 \%$ of the variance would have been explained. 
Table 4. The total variance explained.

\begin{tabular}{cccc}
\hline \multirow{2}{*}{ Factor } & \multicolumn{3}{c}{ Rotation Sums of Squared Loadings } \\
\cline { 2 - 4 } & Eigenvalue & Percentage of Variance & Cumulative Percentage \\
\hline 1 & 4.00 & 24.93 & 24.93 \\
2 & 3.62 & 22.64 & 47.56 \\
3 & 2.29 & 14.29 & 61.85 \\
4 & 1.76 & 10.97 & 72.82 \\
\hline
\end{tabular}

Table 5 shows the rotated factor matrix for the data. The factor loadings measured the relationship between the items and the factors. The factor loadings could have been interpreted as the correlation coefficients, ranging between -1.0 and +1.0 . Tabachnick and Fidell [26] stated that the variables with factor loadings more than 0.45 were chosen in this study because the loadings that were equal to 0.45 were considered average, whereas loadings that were 0.32 were considered as worse. After performing the varimax rotation method using the Kaiser normalization, the first factor comprised of five items with factor loadings ranging from 0.77 to 0.88 , the second factor comprised of six items with factor loadings ranging from 0.52 to 0.91 , third factor comprised of three items with factor loadings ranging from 0.73 to 0.92 , and the fourth factor comprised of two items with factor loadings ranging from 0.546 to 0.813 . The new fourth factors were successfully constructed using the factor analysis and were assigned according to the factors' effects on the development of the SHS.

Table 5. Factor structure of the sustainable SHS development factor weights after varimax rotation.

\begin{tabular}{|c|c|c|c|c|c|}
\hline Items & Item Label & \multicolumn{4}{|c|}{ Factor Loadings } \\
\hline 15 & SHS maintain & 0.88 & - & - & - \\
\hline 14 & SHS usage instruction & 0.82 & - & - & - \\
\hline 8 & SHS helps understand social changes & 0.81 & - & & - \\
\hline 4 & SHS improves the household economy & 0.77 & - & - & - \\
\hline 12 & SHS is the utility suitable for the community & - & 0.81 & - & - \\
\hline 10 & SHS is proper for sufficient lifestyle & - & 0.70 & - & - \\
\hline 5 & The initial investment for SHS installation & - & 0.69 & - & - \\
\hline 2 & Regulations on maintenance and maintenance fee collection & - & 0.65 & - & - \\
\hline 6 & Maintenance fees & - & 0.52 & - & - \\
\hline 3 & Roles of the sub-district administration organization in SHS management & - & - & 0.92 & - \\
\hline
\end{tabular}

Note, factor loadings $>0.50$ are in boldface.

Table 6 shows the name of the new factors and the percentage of variance that has been explained for each of the factors. At the same time, the integrating meaning could be identified directly, which influenced the SHS development of the factors that have been described below.

- The first factor, which met the approval of the SHS technologies, showed the highest percentage of variance when it was extracted. When the first factor, which met the approval of the SHS technologies, $24.93 \%$ of the variances could be explained. The five key items were SHS maintain, SHS device reparation, SHS usage instruction, SHS helps understand social changes, and SHS improves the household economy. This group dealt with education, understanding in the SHS, and the benefits that the society received.

- The second factor was the developing of the SHS management, where $22.64 \%$ of the variances could be explained. The six important items in this group were that the SHS was suitable for remote areas, was the SHS utility suitable for the community, the SHS was proper for a 
sufficient lifestyle, the initial investment for the SHS installation, the regulations on maintenance and maintenance fee collection, and the maintenance fees. The factors in this group dealt with methods to improve the SHS as well as proper community management.

- The third factor was the promoting of SHS technologies, for which $14.29 \%$ of the variances could be explained. The three main items in this group were the roles of the sub-district administration organization in SHS management, continuity in SHS development policies, and SHS maintenance from government officials. It was found that the minor factors in this group contained policies on supporting the use of SHS and giving knowledge about SHS to the community.

- The fourth factor was the supporting of the SHS policies, where $10.97 \%$ of the variances could be explained. Two major factors in this group were the SHS sufficient for increasing users, and the SHS repair/replacement fees. The group's minor factors included the cost of installation and the expense for maintenance.

Table 6. Name of new factors with the percentage of variance.

\begin{tabular}{|c|c|c|c|}
\hline New Factors & Name & $\begin{array}{l}\text { Percentage of } \\
\text { Variance }\end{array}$ & Item Label \\
\hline 1 & $\begin{array}{l}\text { Creating approval of } \\
\text { SHS technologies }\end{array}$ & 24.93 & $\begin{array}{l}\text { 15. SHS maintain } \\
\text { 16. SHS device reparation } \\
\text { 14. SHS usage instruction } \\
\text { 8. SHS helps understand social changes } \\
\text { 4. SHS improves the household economy }\end{array}$ \\
\hline 2 & $\begin{array}{l}\text { Developing of } \\
\text { SHS management }\end{array}$ & 22.64 & $\begin{array}{l}\text { 11. SHS is suitable for remote areas } \\
\text { 12. SHS is the utility suitable for the community } \\
\text { 1. SHS is proper for sufficient lifestyle } \\
\text { 5. The initial investment for SHS installation } \\
\text { 2. Regulations on maintenance and maintenance } \\
\text { fee collection } \\
\text { 6. Maintenance Fees }\end{array}$ \\
\hline 3 & $\begin{array}{l}\text { Promoting of } \\
\text { SHS technologies }\end{array}$ & 14.29 & $\begin{array}{l}\text { 3. Roles of the sub-district administration } \\
\text { organization in SHS management } \\
\text { 1. Government's continuity in SHS } \\
\text { development policies } \\
\text { 13. SHS maintenance from government officials }\end{array}$ \\
\hline 4 & $\begin{array}{l}\text { Supporting of } \\
\text { SHS policies }\end{array}$ & 10.97 & $\begin{array}{l}\text { 9. SHS sufficient for increasing users } \\
\text { 7. SHS repair/replacement fees }\end{array}$ \\
\hline
\end{tabular}

Table 6 was used to create a conceptual framework for the development of strategy that was sustainable for SHS. This strategy recommended the cooperation of all of the sectors, companies, communities, and governments as leaders of social acceptance.

Figure 7 shows a significant development strategy for sustainable SHS in the Akha upland community of Thailand. It was designed from the bottom up, which this approach used to create a sustainable development network in the Akha community. The organizations and the sub-district administrative organization (SAO) could be more organized based upon the strategies of those elements so as to determine the priority of the problem-solving. The following were four development strategies for sustainable SHS:

- $\quad$ The first priority was creating the approval of SHS technologies;

- The second priority was the development of the SHS management;

- The third priority was promoting the SHS technologies; and

- The fourth priority was supporting the SHS policies. 


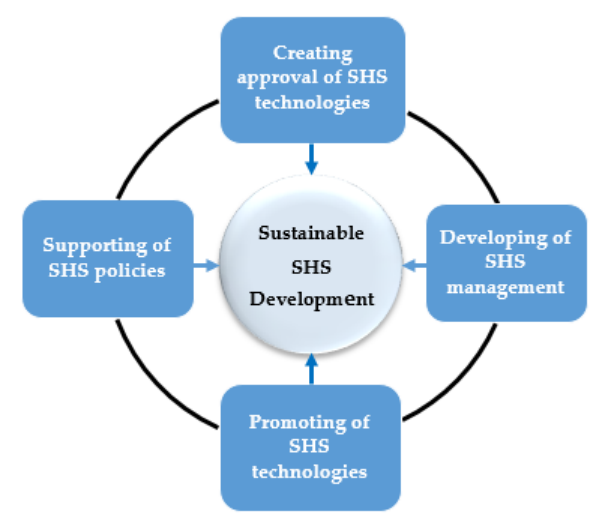

Figure 7. Framework of development strategy for sustainable SHS.

However, the experts from the field recommend a follow-up study to empirically assess the provided sustainable SHS development within the innovation of the education domain. It should consist of six steps, as follows: step 1, survey areas and understand electricity demand from the bottom up; step 2, study the solar resource potentials and design technology that would be appropriate for the end-users; step 3, a social impact assessment from the SHS technology; step 4, create awareness of the social benefits of the SHS; step 5, evaluation of the SHS knowledge and ability management; and step 6, community planning that was appropriate for SHS management. The result of the sustainable SHS development process and evaluation would lead to the effective policy of promoting renewable energy. According to the validity section, it should be discussed how one might be wrong in order to remain critical of one's own work [27].

\section{Discussion}

According to the results of the study, it was concluded that most of the user households $(79.38 \%)$ were the people of Akha hill tribe who were uneducated, had a low income, and who had never received information about SHS. The causes for this could have been the lack of personnel in the sub-district administrative organization that were proficient in SHS operation and maintenance. The second cause was that $74.13 \%$ of the community was not easy to transport. The battery deterioration as the main source of the technical problem was about $43.30 \%$. In addition, the Akha community had limited knowledge regarding renewable technology, as well as a lack of understanding and maintenance of the SHS, thus affecting the process of the SHS development. As a result, the end-users had a negative attitude toward the SHS because such permitted energy could not support quality of life (QoL) in those end-users. In relation to the policymakers should understand the purpose of end-users about energy consumption [28]. It had considered to be the most important and related to end-users opinions on developing alternative energy technologies [29]. In addition, the results showed that development strategy for sustainable SHS should be composed of social factors, which consisted of SHS education, an understanding of SHS, and the benefits the society receives. If public community improved, this would lead to the social acceptance of the SHS technology. Next, the economic factors needed methods to improve the SHS and suitable community management. After that, the technological factors needed to contain policies on supporting SHS development and providing knowledge about SHS to the community. The last strategy was the policy factor, which included the cost of installation and the expense for maintenance. These factors contributed to the strategic development of SHSs. This could be a result from bottom up approach. In addition, if the end-users had negative attitudes and a lack of knowledge of alternative energy technologies, it was difficult to develop SHSs in the Akha community. According to the skilled technicians, another important obstacle was the after-sales services. Because of the presence of plentiful producers (local and foreign), standard component testing was highly recommended. The maintenance of a standard quality would have increased the lifetime of SHSs and also made the SHSs more feasible for use in the future [30]. 
In this way, the policy maker should be open to experiences with SHSs. It would have a positive attitude and lead to social acceptance of solar technology in the community [31] Therefore, the SHS sustainable development strategy was an elective target for the implementation of solar energy technologies. In addition, at the end of the study, the experts recommended that the relevant government agencies reviewed the SHS development work plan, which should have address the basic needs of the community in the development of renewable energy technologies. It implied proper management and continuous monitoring to ensure sustainable energy management [32]. In addition, the study also found that the policy makers could obtain subsidies for SHS social recognition. Energy research was also distorted by social sciences, such as engineering and economics [29]. The limitations of the framework were based on the transparent and reproducible procedure [33] followed the case of a leading sustainable SHS development in difference areas. As such, this strategy framework was specific to the Akha upland community of Thailand, and it was difficult to make generalizations from a single case study. On the other hand, the social sciences tended to frame energy acceptance studies from particular perspectives [34]. While complete unanimity of theoretical perspectives in this context was not possible, there was arguably a role for conceptual frameworks that categorized the many factors that were identified as influencing social and public acceptance of emerging energy technologies [35]. Nevertheless, such frameworks were able to span the categories of acceptance of energy technologies and were able to facilitate and encourage simultaneous consideration of the multiple influences on attitudes and behaviors. This, in turn, was a precondition for seeking to understand the relative and interacting effects of the variables of interest to most energy social science researchers, regardless of their discipline [36]. To increase the power generation as the end user requirements, the hybrid system between PV and other renewable energy system is needed. In order to sustain the using of hybrid renewable energy, the knowledge transfer to SAO and people in community and the encouraging people are required to maintain the proposed hybrid renewable energy in further study.

\section{Conclusions and Recommendation}

We have offered a development strategy for the sustainable SHS associated research problems and directions in this light. This paper has shared the problem of the SHS development experience in the Akha upland community of Thailand. We have also raised some pertinent issues and have attempted to find solutions to this issue. We have suggested a development strategy for sustainable SHS associated research problems and directions in this light (by resident, properly instituted decision makers). This has indicated that the public attitude does not hinder the progress of solar energy technology. We should attempt to better to understand the dynamics of public engagement in renewable energy technological development. This can be facilitated by inter-disciplinary research, using innovative qualitative and quantitative social research methods, with a greater emphasis upon the symbolic, effective, and socially-constructed nature of the beliefs regarding renewable energy technologies. Designers and researchers should track and monitor the SHS for receiving the feedback from community groups regarding their involvement in the process. However, the impact of environmental, economic, social, political, and technical factors has led to the rapid development of energy substitution. Therefore, further research in the field should focus on the development of new methods and tools so as to integrate these new models. Included are studies on renewable energy sources from different disciplines and theoretical perspectives in order to develop a more structured understanding of what identifies renewable energy conflicts [37].

Author Contributions: P.B. and H.O. have developed the concept and designed the study. While data collection, supervision of the survey implementation, writing, and analysis was done by P.B., the manuscript was proofread and revised by all of the authors. All of the authors read and approved the final manuscript.

Acknowledgments: This article is based on a research project titled 'Environmental impact factor modeling for sustainable development of Thailand's solar home system. The author acknowledges the funding provided to the research project by the National Research Council of Thailand (Grant No. 146610).

Conflicts of Interest: The authors declare no conflict of interest. 


\section{References}

1. Schelly, C. Frameworks for Understanding and Promoting Solar Energy Technology Development. Resources 2015, 4, 55-69. [CrossRef]

2. Gonzalez, G.A. Energy and Empire: The Politics of Nuclear and Solar Power in the United States; State University of New York Press: Albany, NY, USA, 2012.

3. Reece, R. The Sun Betrayed: A Report on the Corporate Seizure of U.S. Solar Energy Development; South End Press: Boston, MA, USA, 1979.

4. Pearce, J.M. Photovoltaic: A path to sustainable futures. Futures 2002, 34, 663-674. [CrossRef]

5. Alternative Energy Development Plan (AEDP2015). Available online: http://www.dede.go.th/download/ files / AEDP\%20Action\%20Plan_Final.pdf (accessed on 25 March 2018).

6. Sample Application of Solar Home System. Available online: http://www.leonics.com/system/solar photovoltaic/solar_home_system/shs-00130_en.php (accessed on 5 May 2018).

7. Watjanatepin, N.; Boonmee, C.; Unhalekha, P.; Srisongkhram, V.; Kurehong, T.; Wannasut, C. Evaluation of electrical service acceleration project by the solar home system in Thailand. In Proceedings of the 4th Conference on Energy Technology Network of Thailand E-NETT, Nakronpatom, Thailand, 14-16 May 2008.

8. Iemsomboon, P.; Waiprom, N.; Ngaemngam, S.; Bhumkittipich, K. A Report on Environmental Impact Factor Modeling for Sustainable Development of Solar Home System; RMUTT: Pathumtani, Thailand, 2015.

9. Banos, R.; Manzano-Agugliaro, F.; Montoyab, F.G.; Gila, C.; Alcayde, A.; Gómez, J. Optimization methods applied to renewable and sustainable energy: A review. Renew. Sustain. Energy Rev. 2011, 15, 1753-1766. [CrossRef]

10. Annika, S.; Mats, L.; Alf, R.; Marcus, L.; Rafael, W. On the physics of power, energy, and economics of renewable electric energy sources-PART II. Renew. Energy 2010, 35, 1735-1740. [CrossRef]

11. Panwara, N.L.; Kaushikb, S.C.; Surendra, K. Role of renewable energy sources in environmental protection: A review. Renew. Sustain. Energy Rev. 2011, 15, 1513-1524. [CrossRef]

12. Konishi, R.; Takahashi, M. Optimal Allocation of Photovoltaic Systems and Energy Storage Systems based on Vulnerability Analysis. Energies 2017, 10, 1477. [CrossRef]

13. Moula, M.M.E.; Maula, J.; Hamdy, M.; Fang, T.; Jung, N.; Lahdelma, R. Researching social acceptability of renewable energy technologies in Finland. Int. J. Sustain. Built Environ. 2013, 2, 89-98. [CrossRef]

14. Sustainability Assessment Framework for Renewable Energy Technology. Available online: www.reading.ac. uk/web/FILES/tsbe/Luong_TSBE_Conference_Paper_2012.pdf (accessed on 25 March 2018).

15. Liu, G.; Li, M.; Zhou, B.; Chen, Y.; Liao, S. Development of a general sustainability indicator for renewable energy systems: A review. Renew. Sustain. Energy Rev. 2014, 31, 611-621. [CrossRef]

16. Qin, X.D.; Zhang, Y.H.; Lei, J. Review of research on sustainable community. Appl. Mech. Mater. 2013, 168, 102-106. [CrossRef]

17. Njoroge, J.K.; Ongeti, W.J.; Kinuu, D.; Kasomi, F.M. Does External Environment Influence Organizational Performance? The Case of Kenyan State Corporations. Manag. Organ. Stud. 2016, 3, 41-51. [CrossRef]

18. PESTLE Analysis. 2013; ISBN 978-1-62620-998-5. Available online: http://www.free-management-ebooks. com/dldebk-pdf/fme-pestle-analysis.pdf (accessed on 5 April 2018).

19. Iemsomboon, P. Modeling Community Quality of Life Indicators for Developing Solar Home System in Remote Areas. Ph.D. Thesis, Kasetsart University, Bangkok, Thailand, 2012.

20. Determining Sample Size. Available online: http://www.psycholosphere.com/Determining $\% 20$ sample\% 20size\%20by\%20Glen\%20Israel.pdf (accessed on 20 May 2018).

21. Phei-Chin, P.; Kulathuramaiyer, N.; Iskandar, D.N.F.A.; Leng, C.K. Towards semantic clustering: Grouping image visual features through exploratory factor analysis. In Proceedings of the IIEEJ Image Electronics and Visual Computing Workshop, Kuching, Malaysia, 21-24 November 2012.

22. Fields, Z. A Conceptual Framework to Measure Creativity at Tertiary Educational Level. Ph.D. Thesis, North-West University, Potchefstroom, South Africa, 2013.

23. Yalçın, M.T.; Ereş, F. A Study of Validity and Reliability on the Instructional Capacity Scale. Univers. J. Educ. Res. 2018, 6, 57-67. [CrossRef]

24. Bentler, P.M.; Kano, Y. On the Equivalence of Factors and Components. Multivar. Behav. Res. 1990, 25, 67-74. [CrossRef] [PubMed] 
25. Young, A.G.; Pearce, S. A beginner's guide to factor analysis: Focusing on exploratory factor analysis. Tutor. Quant. Methods Psychol. 2013, 9, 79-94. [CrossRef]

26. Tabachnick, B.G.; Fidell, L.S. Using Multivariate Statistics, 4th ed.; Allyn and Bacon, Incorporated: Boston, MA, USA, 2000; ISBN 0321056779.

27. Maxwell, J.A. Qualitative Research Design: An Interactive Approach; Sage Publications, Inc.: Thousand Oaks, CA, USA, 2005.

28. Iemsomboon, P.; Tangtham, N.; Kanjanasuntorn, S.; Bualert, S. Modeling community quality of life indicators for developing solar home system in remote areas. Energy Procedia 2011, 9, 44-55. [CrossRef]

29. Meenakorn, S. A Report on the Study Pattern Energy Management Appropriate for Amphawa District; Suan Sunandha Rajabhat University: Bangkok, Thailand, 2012.

30. Kabir, E.; Ki-Hyun, K.; Szulejko, J.E. Social Impacts of Solar Home Systems in Rural Areas: A Case Study in Bangladesh. Energies 2017, 10, 1615. [CrossRef]

31. Bertsch, V.; Hyland, M.; Mahony, M. What drives people's opinions of electricity infrastructure? Empirical evidence from Ireland. Energy Policy 2017, 106, 472-497. [CrossRef]

32. Singhonniyom, S.; Thamsatitdej, P. Factors Affecting Behavior Recognition Technology to Generate Electricity with Solar Cells. In Proceedings of the Graduate Research Conference, Khon Kheng, Thailand, 8-10 December 2014; pp. 536-544.

33. Transfield, D.; Denyer, D.; Smart, P. Towards a methodology for developing evidence-informed management knowledge by means of systematic review. Br. J. Manag. 2003, 14, 207-222. [CrossRef]

34. Wilson, C.; Dowlatabadi, H. Models of Decision Making and Residential Energy Use. Annu. Rev. Environ. Resour. 2007, 32, 169-203. [CrossRef]

35. Stern, PC. Individual and household interactions with energy systems: Toward integrated understanding. Energy Res. Soc. Sci. 2014, 1, 41-48. [CrossRef]

36. Devine-Wright, P.; Batel, S.; Aas, O.; Sovacool, B.; La Belle, M.C.; Ruud, A. A conceptual framework for understanding the social acceptance of energy infrastructure: Insights from energy storage. Energy Policy 2017, 107, 27-31. [CrossRef]

37. Kahn, J. Siting conflicts in renewable energy projects in Sweden: Experiences from the siting of a Biogas plant. In Proceedings of the New Perspectives on Siting Controversy Conference, Glumslov, Sweden, 17-20 May 2001.

(C) 2018 by the authors. Licensee MDPI, Basel, Switzerland. This article is an open access article distributed under the terms and conditions of the Creative Commons Attribution (CC BY) license (http://creativecommons.org/licenses/by/4.0/). 